\title{
Stress Degradation Behavior of a Polypill and Development of Stability Indicating UHPLC Method for the Simultaneous Estimation of Aspirin, Atorvastatin, Ramipril and Metoprolol Succinate
}

\author{
Satheesh Kumar Shetty ${ }^{1,5}$, K. V. Surendranath ${ }^{1}$, P. Radhakrishnanand ${ }^{1}$, Roshan M. Borkar ${ }^{2}$, \\ Prashant S. Devrukhakar ${ }^{2}$, Johnson Jogul ${ }^{3}$, Upendra Mani Tripathi ${ }^{4}$ \\ ${ }^{1}$ United States Pharmacopeia-India Private Limited, Research and Development Laboratory, ICICI Knowledge Park, \\ Turkapally, Shameerpet, Hyderabad, India \\ ${ }^{2}$ NIPER Instititute of Pharmaceutical sciences, Hyderabad, India \\ ${ }^{3}$ Department of Chemistry, St. Kittel Science College, Dharwad, Karnataka, India \\ ${ }^{4}$ Startech Labs private Limited, SMR Chambers Madinaguda, Hyderabad, India \\ ${ }^{5}$ Department of Chemistry, Jawaharlal Nehru Technological University, Kukatpally, Hyderabad, India \\ E-mail: Skshetty69@rediffmail.com,sks@usp.org. \\ Received October 6, 2010; revised November 25, 2010; accepted December 5, 2010
}

\begin{abstract}
A novel, sensitive and precise UHPLC method has been developed and validated for the simultaneous determination of the all the active components of a Polypill viz Zycad, i.e., Aspirin (ASP) Atorvastatin (ATV), Ramipril (RMP) and Metoprolol (MTP) in Zycad tablet dosage form in the presence of degradation products. Forced degradation of individual as well as combination of all the drug substances components of Polypill was conducted in accordance with ICH guidelines. Acidic, basic, neutral, and oxidative hydrolysis, thermal stress, and photolytic degradation were used to assess the stability-indicating power of the method. Use of $100 \times 2.1 \mathrm{~mm}, 1.7 \mu \mathrm{m}$ stationary phases with simple mobile phase combination buffer consisting of $0.1 \%$ Perchloric acid (adjusted to $\mathrm{pH} 2.5$ ) and Acetonitrile, delivered in a gradient mode and quantitation was carried out using ultraviolet detection at $215 \mathrm{~nm}$ with a flow rate of $0.6 \mathrm{~mL} \cdot \mathrm{min}^{-1}$. The method was optimized using samples generated by forced degradation studies. The method was validated for linearity, accuracy (recovery), precision, Specificity and robustness. The method was linear in the range of 37.5 to 150.0 $\mu \mathrm{g} \cdot \mathrm{mL}^{-1}$ for ASP, 5.0 to $20.0 \mu \mathrm{g} \cdot \mathrm{mL}^{-1}$ for ATV and 2.5 to $10.0 \mu \mathrm{g} \cdot \mathrm{mL}^{-1}$ for RMP and 25.0 to $100.0 \mu \mathrm{g} \cdot \mathrm{mL}^{-1}$ for MTP.
\end{abstract}

Keywords: Liquid Chromatography; UHPLC, Polypill, Aspirin, Atorvastatin, Ramipril and Metoprolol Succinate, Forced Degradation, Validation, Stability Indicating

\section{Introduction}

Ultra-high performance liquid chromatography is a new category of separation technique based upon wellestablished principles of liquid chromatography, which utilizes sub-2 $\mu \mathrm{m}$ particles for stationary phase. These particles operate at elevated mobile phase linear velocities to affect dramatic increase in resolution, sensitivity $\&$ speed of analysis. Polypill is a fixed dose combination, used as a single daily pill to achieve a large effect in preventing cardiovascular disease with minimal adverse effects. The concept has been applied to pharmaceutical formulations in recent days [1-6]. In the present work, the UHPLC technology has been applied for the fast estimation of the four main components of Polypill viz, Zycad in a single method.

Zycad is a fixed dose combination of Aspirin (ASP), Atorvastatin (ATV), Ramipril (RMP) and Metoprolol Succinate (MTP). Each Zycad Polypill kit contains Aspirin $75 \mathrm{mg}$, Atorvastatin $10 \mathrm{mg}$, and Ramipril $5 \mathrm{mg}$ in a single Capsule form and Metoprolol Succinate $50 \mathrm{mg}$ as separate tablet. Aspirin (ASP), 2-acetoxybenzoic acid 
has an antiplatelet effect by inhibiting the production of thromboxane, which under normal circumstances binds platelet molecules together to create a patch over damaged walls of blood vessels. This effect lasts for the life of the platelet and prevents the formation of the platelet aggregating factor thromboxane A2 [6,7]. Atorvastatin (ATV), (3R,5R)-7-[2-(4-fluorophenyl)-3-phenyl-4-(phenylcar-bamoyl)-5-(propan-2-yl)-1H-pyrrol-1-yl]-3,5-Dihydroxy-hep -tanoic acid is a member of the drug class known as statins, used for lowering blood cholesterol. It also stabilizes plaque and prevents strokes through anti-inflammatory and other mechanisms. Atorvastatin works by inhibiting HMG-CoA reductase, an enzyme found in liver tissue that plays a key role in production of cholesterol in the body. This enzyme catalyzes the conversion of HMGCoA to mevalonate, an early and rate limiting step in the synthesis of cholesterol [8]. Ramipril(RMP), 2S, 3aS, 6aS)-1-[(2S)-2- $\{[(2 S)-1-$ ethoxy-1-oxo-4-phenylbutan-2yl]amino propanoyl]-octahydrocyclopenta[b]pyrrole-2carboxylic acid is a prodrug and is converted to the active metabolite ramiprilat by liver esterase enzymes is an angiotensin-converting enzyme (ACE) inhibitor, used to treat hypertension and congestive heart failure [9]. Metoprolol (MTP), (RS)-1-(iso-propyl amino)-3-[4-(2ethoxyethyl) phenoxy] Propan-2-ol is a selective $\beta_{1}$ receptor blocker used in treatment of the cardiovascular system, especially hypertension.Due to its selectivity in blocking the beta receptors in the heart, Metoprolol is also prescribed for off-label use in performance anxiety, social anxiety disorder, and other anxiety disorders [10].

Though there were lot of papers published for the individual estimation of the drug substances ASP, ATV, RMP and MTP in pharmaceutical preparations, Literature survey did not reveal any simple, sensitive and stability indicating LC method for the simultaneous determination of all the four drugs as a fixed dose combination. Literature survey reveals that a variety of spectrophotometric and chromatographic, stability indicating LC method has been reported for determination of these individual drug components as well as combination of two or three drugs in pharmaceutical dosage forms [11-16]. The present drug stability test guideline Q1A (R2) [17,18] issued by International Conference on Harmonization (ICH) suggests that stress studies should be carried out on a drug to establish its inherent stability characteristics, leading to the development of a separation method for the degradation products and hence to support the stability indicating nature of the method.

This manuscript describes the development and validation, in accordance with ICH guidelines, of a rapid, economical, precise, and accurate stability-indicating reversed-phase UHPLC method for the estimation of Aspirin (ASP), Atorvastatin (ATV), Ramipril (RMP) and
Metoprolol Succinate (MTP) in Zycad along with method validation.

\section{Experimental}

\subsection{Chemicals}

Pure Samples of Aspirin (ASP) Atorvastatin (ATV), Ramipril (RMP) and Metoprolol Succinate (MTP) with purity more than $99.5 \%$ were kindly supplied by USP India (P) limited, Hyderabad, India (Figure 1). Zycad Polypill kits were purchased from the Market. HPLC grade Acetonitrile, Perchloric acid and triethylamine was purchased from Merck Germany. Milli-Q water prepared by using Millipore purification system.

\subsection{Equipment}

Waters AQUITY UPLC binary pump plus auto sampler and an AQUITY photo diode array detector were used during the method development, Stress studies and for method validations. Empower software (Digital equipment $\mathrm{Co}$ ) was used to monitor and process the output signal. Controlled temperature oven (Mack Pharmatech Private Ltd., Mumbai, India) was used for solid state thermal stress studies. Photo stability studies were carried out in a photo stability chamber (Mack Pharmatech, Hyderabad, India.

\subsection{Chromatographic Conditions}

The Chromatographic separations were achieved on a Waters Acquity UPLC BEH C18 Column $(100 \times 2.1) \mathrm{mm}$ with $1.7 \mu \mathrm{m}$ particles. $0.1 \%$ Perchloric acid (adjusted pH.2.5) used as solution A \& Acetonitrile as solution B in gradient mode. Flow rate of the mobile phase was $0.6 \mathrm{~mL}$ $\mathrm{min}^{-1}$. The UHPLC gradient program was set as: (time (min)/\% solution B: 0/10, 1.0/60, 1.5/80, 2.0/60, 2.5/10, $3.0 / 10$. The column temperature was maintained at $35^{\circ} \mathrm{C}$ $\&$ the detection was monitored at a wavelength of $215 \mathrm{~nm}$. The injection volume was $2 \mu \mathrm{L}$. Buffer: Acetonitrile in the ratio $80: 20 \mathrm{v} / \mathrm{v}$ was used as the diluent.

\subsection{Preparation of Standard Solutions}

Working solutions $0.075 \mathrm{mg} \cdot \mathrm{mL}^{-1}$ of ASP, $0.01 \mathrm{mg} \cdot \mathrm{mL}^{-1}$ of ATV, $0.005 \mathrm{mg} \cdot \mathrm{mL}^{-1}$ of RMP and $0.05 \mathrm{mg} \cdot \mathrm{mL}^{-1}$ of MTP were prepared from the stock solutions 7.5 $\mathrm{mg} \cdot \mathrm{mL}^{-1}$ of ASP, $1 \mathrm{mg} \cdot \mathrm{mL}^{-1}$ of ATV, $0.5 \mathrm{mg} \cdot \mathrm{mL}^{-1}$ of $\mathrm{RMP}$, and $5 \mathrm{mg} \cdot \mathrm{mL}^{-1}$ of MTP.

\subsection{Preparation of Sample Solutions}

The contents of twenty Capsules and MTP tablets were weighed to determine the average weight of the single 


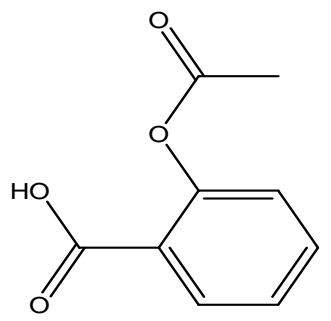

(a)

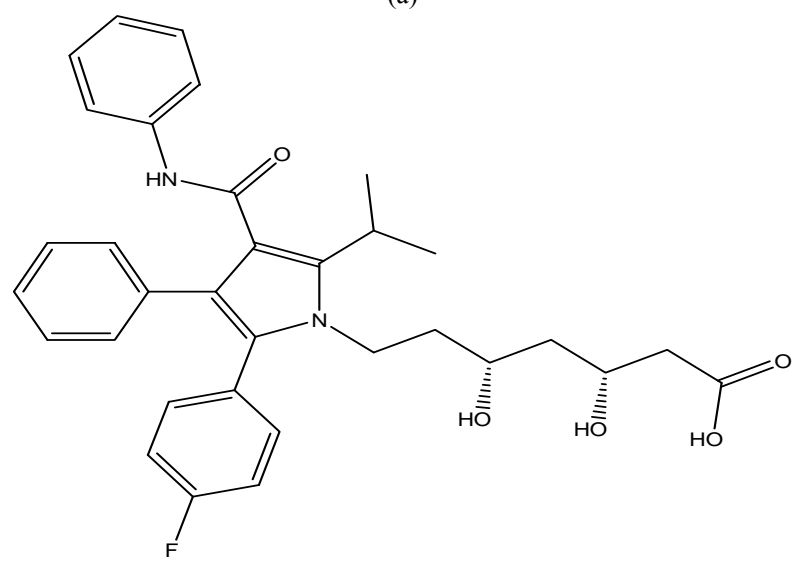

(b)

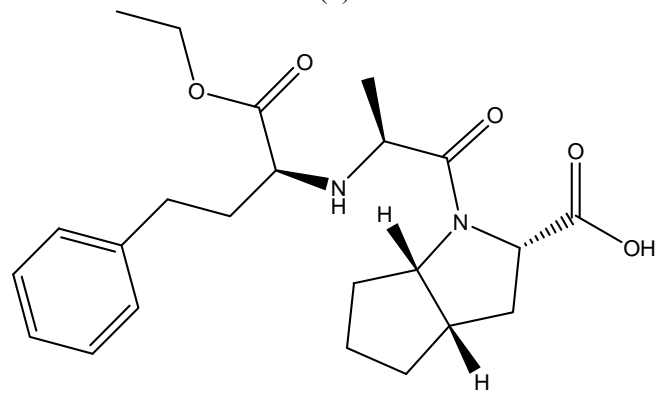

(c)

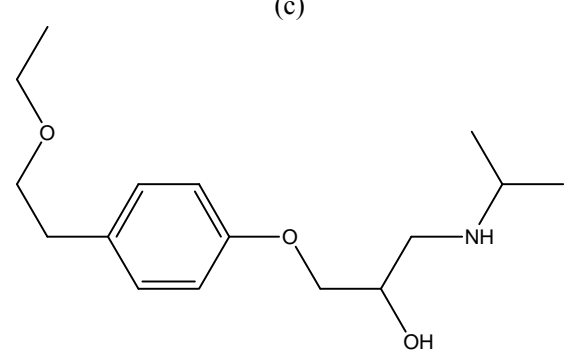

(d)

Figure 1. Chemical structures and labels of all the drug substances: ASP, ATV, RMP and MTP (a) Aspirin (ASP): 2-acetoxybenzoic acidM.F: $\mathrm{C}_{9} \mathrm{H}_{8} \mathrm{O}_{4} \quad$ M.W: $180.16 \mathrm{~g} \cdot \mathrm{mol}^{-1}$; (b) Atorvastatin (ATV): (3R, 5R)-7-[2-(4-fluorophenyl)3-phenyl-4-(phenylcarbamoyl)-5-(propan-2-yl)-1H-pyrrol-1 -yl]-3,5-dihydroxyheptanoic acid. M.F: $\mathrm{C}_{33} \mathrm{H}_{35}$ F $\mathrm{N}_{2} \mathrm{O}_{5}$ M.W: $558.64 \mathrm{~g} \cdot \mathrm{mol}^{-1}$; (c) Ramipril (RMP): $(2 S, 3 a S, 6 a S)-1-$ [(2S)-2-\{[(2S)-1-ethoxy-1-oxo-4-Phenylbutan-2-yl]amino\} propanoyl]-octahydrocyclopenta[b] pyrrole-2-carboxylic acid M.F: $\mathrm{C}_{23} \mathrm{H}_{32} \mathrm{~N}_{2} \mathrm{O}_{5}$ M. W: $416.51 \mathrm{~g} \cdot \mathrm{mol}^{-1}$; 9d) Metoprolol (MTP): (RS)-1-(isopropyl amino)-3-[4-(2-ethoxyethyl) phenoxy] Propan-2-ol $\mathrm{C}_{15} \mathrm{H}_{25} \mathrm{NO}_{3}$.W: $267.34 \mathrm{~g} \cdot \mathrm{mol}^{-1}$. dosage unit. The contents of the Capsules and tablets were crushed to a homogeneous powder and a quantity equivalent to one dosage form (i.e. Equivalent to $75 \mathrm{mg}$ ASP, $10 \mathrm{mg}$ ATV, $5 \mathrm{mg}$ RMP and $50 \mathrm{mg}$ MTP) was weighed in to a $100-\mathrm{mL}$ volumetric flask, extracted in diluents by sonicating for $10 \mathrm{mins}$, and filtered through Whatman no. 41 filter paper. The $1 \mathrm{ml}$ of the clear filtrate) was quantitatively transferred to a $10-\mathrm{mL}$ volumetric flask, and solution was diluted to volume with the diluent.

\subsection{Analytical Method Validation}

The method was validated for specificity, precision, sensitivity, linearity, accuracy, robustness, and system suitability.

Forced degradation studies were performed on individual as well as mixture of all the four drugs, to provide an indication of stability indicating property and specificity of the proposed method [19,20].

Acid hydrolysis was performed in $0.1 \mathrm{~N} \mathrm{HCl}$ at reflux condition for $1 \mathrm{~h}$. Basic hydrolysis was performed in $0.1 \mathrm{~N}$ $\mathrm{NaOH}$ at reflux condition for $0.5 \mathrm{~h}$.

For studies in oxidation condition, the drug combinations were exposed to $5 \% \mathrm{H}_{2} \mathrm{O}_{2}$. RT for $8 \mathrm{~h}$. Photolytic degradation studies were performed carried out as per ICH Q1B.The dug samples was exposed to light for overall illumination of $1.2 \times 10^{6} \mathrm{lux} \mathrm{h}$ and an integrated near ultraviolet energy of $200 \mathrm{~W} \mathrm{~h} \mathrm{~m}^{2}$.

To study the thermal degradation the drug combinations were exposed to dry heat at $60^{\circ} \mathrm{C}$. Peak purity of stressed samples was checked by using a Acquity photo diode array detector (PDA). All stressed samples were analyzed for extended run time $(30 \mathrm{~min})$ to check for late-eluting degradation products.

Initially, system suitability was prepared, by dissolving appropriate amounts of all the four standard drug substances in the diluents to get a final concentration of 75 $\mu \mathrm{g} \cdot \mathrm{mL}^{-1}$ ASP, $10 \mu \mathrm{g} \cdot \mathrm{mL}^{-1}$ ATV , $5 \mu \mathrm{g} \cdot \mathrm{mL}^{-1} \mathrm{RMP}$, and 50 $\mu \mathrm{g} \cdot \mathrm{mL}^{-1} \mathrm{MTP}$, and injecting into the LC system and evaluating the criteria like Resolution, USP Tailing factor and No. of theoretical plates for each drug component. The optimized method was validated with respect to various parameters summarized in the ICH guideline Q2 (R1).

The precision of the assay method was checked by injecting the 6 replicates of the sample preparations of the commercial tablet (Zycad).Repeatability (Intra-Day precision) of the assay method was evaluated by carrying out six independent assays of the commercial tablets with concentrations $0.075 \mathrm{mg} \cdot \mathrm{mL}^{-1}$ of ASP, 0.01 $\mathrm{mg} \cdot \mathrm{mL}^{-1}$ of ATV, $0.005 \mathrm{mg} \cdot \mathrm{mL}^{-1}$ of RMP and 0.05 $\mathrm{mg} \cdot \mathrm{mL}^{-1}$ of MTP, against qualified reference standard 
and calculating the \% RSD of the assay results. Intermediate precision (ruggedness) was evaluated by conducting precision studies using different analysts and different columns in the same laboratory.

LOD and LOQ for ASP, ATV, RMP, and MTP were estimated by injecting a series of dilute solutions with known concentrations. The precision study was also carried out at the LOQ level by injecting six individual preparations and calculating the RSD (\%) of peak area for each drug components.

To establish linearity and range, a stock solution containing $150 \mu \mathrm{g} \cdot \mathrm{mL}^{-1} \mathrm{ASP}, 20 \mu \mathrm{g} \cdot \mathrm{mL}^{-1} \mathrm{ATV}, 10 \mu \mathrm{g} \cdot \mathrm{mL}^{-1}$ RMP, $100 \mu \mathrm{g} \cdot \mathrm{mL}^{-1}$ MTP in methanol was diluted to yield solutions in the concentration range of 37.5 to $150.0 \mu \mathrm{g} \cdot \mathrm{mL}^{-1}$ for ASP, 5.0 to $20.0 \mu \mathrm{g} \cdot \mathrm{mL}^{-1}$ for ATV and 2.5 to $10.0 \mu \mathrm{g} \cdot \mathrm{mL}^{-1}$ for RMP and 25.0 to 100.0 $\mu \mathrm{g} \cdot \mathrm{mL}^{-1}$ for MTP (i.e. 50 to $200 \%$ of analyte concentrations). The solutions were prepared and analyzed in triplicate. Peak-area and concentration data were used to plot the calibration graph and by least squares linear regression analysis, the correlation coefficients, slope and intercept values were calculated.

For determination of accuracy, recovery studies were carried out by spiking analysis. Known amounts of each drug corresponding to $50 \%, 100 \%$, and $150 \%$ of the target test concentrations i.e. $75 \mu \mathrm{g} \cdot \mathrm{mL}^{-1}$ ASP, $10 \mu \mathrm{g} \cdot \mathrm{mL}^{-1}$ ATV, $5 \mu \mathrm{g} \cdot \mathrm{mL}^{-1} \mathrm{RMP}$, and $50 \mu \mathrm{g} \cdot \mathrm{mL}^{-1}$ MTP were added to a placebo mixture the sample was extracted, and the assay was evaluated against the standard and percentage recovery was calculated.

Robustness was tested using the so-called "one factor at a time" method. The factors evaluated were flow rate, column temperature and $\mathrm{pH}$. The experimental conditions were deliberately changed and the relative standard deviation for replicate injections of ATL, ASP, RMP and MTP peaks and the USP resolution factor between MTP and ASP peaks were evaluated. The mobile phase flow rate was $0.6 \mathrm{~mL} \cdot \mathrm{min}^{-1}$. This was changed by 0.05 units to 0.55 and $0.65 \mathrm{~mL} \cdot \mathrm{min}^{-1}$. The effect of column temperature was studied at $40^{\circ} \mathrm{C}$ and $30^{\circ} \mathrm{C}$ instead of $35^{\circ} \mathrm{C}$. The effect of buffer $\mathrm{pH}$ was studied at $\mathrm{pH} 2.4$ and 2.6 .

The solution stability of ASP, ATV, RMP and MTP was carried out by leaving the test solution in tightly capped volumetric flasks at room temperature for $48 \mathrm{~h}$ and assayed at $6 \mathrm{~h}$ interval, against the freshly prepared standard solution. The mobile phase stability was carried out by assaying the freshly prepared sample solution against the freshly prepared standard at $6 \mathrm{~h}$ interval up to $48 \mathrm{~h}$. The percentage of RSD of assay of ASP, ATV, RMP and MTP was calculated for the study period during mobile phase and solution stability experiments.

\section{Results and Discussions}

\subsection{Method Development and Optimization}

A detection wavelength of $215 \mathrm{~nm}$ was used for method development work. This was established by preparing $100 \mu \mathrm{g} \cdot \mathrm{mL}^{-1}$ solutions of each individual drug components of the formulation and scanning in UV-Visible spectrometer.

Initial experiments during the analytical method development reveals that the critical challenge is to obtain adequate retention for the polar parent compound, MTP and ASP, while maintaining a reasonable elution time for the less-polar Atorvastatin (ATV) and to separate one of the degradation impurity Salicylic acid (SA) from the ASP peak.

The ACQUTY UPLC BEH C18 $(50 \times 2.1) \mathrm{mm} 1.7 \mathrm{um}$ Column was chosen for initial trial with $0.1 \%$ Formic acid and Acetonitrile as the mobile phase. Different mobile phase compositions containing Formic acid and Acetonitrile (50:50-20:80 v/v) were tried. But was not successful in getting the good peak shapes for the Ramipril (RMP). There were no improvements in the peak shape of the RMP even under different $\mathrm{pH}$ of the buffer. Using of $0.1 \%$ Orthophosphoric acid as buffer also unsuccessful in obtaining good peak shape for RMP. Although good separation was achieved with $25 \mathrm{mM}$ Sodium perchlorate: Acetonitrile in the gradient mode, Atorvastatin and Ramipril peak symmetry was found to be greater than 2.0. The asymmetries of the peaks were improved by addition of Triethylamine (TEA) and adjusting the mobile phase $\mathrm{pH}$ to 2.5 in the aqueous phase.

The chromatographic separation with better peak shape was achieved using a mixture of aqueous $0.1 \%$ Perchloric acid and Acetonitrile in the ratio of 40:60 $(\mathrm{v} / \mathrm{v})$. However to improve the resolution between the closely eluting peaks, the method was changed to gradient mode and optimized the gradient conditions. But when stressed samples injected with this optimized conditions, it was found that some of the degradants, co eluted with the principal peaks. So the length of the column is increased to $100 \mathrm{~mm}$ and the method was optimized to separate all the degradants from the main peaks by changing to Gradient mode. Several gradient conditions were tried before optimizing the final gradient programme as: time $(\mathrm{min}) / \%$ solution B: $0 / 10,1.0 / 60$, 1.5/80, 2.0/60, 2.5/10, 3.0/10.

As peak shape of Atenolol (ATL) was one of the issue even after optimizing the LC parameters, effect of the diluent on the peak shapes was studied by changing so many combinations of the diluents. The ATL peak was observed as split in most of the compositions of the buffer 
and Acetonitrile. Finally Buffer: Acetonitrile in the ratio $80: 20, \mathrm{v} / \mathrm{v}$, was optimized as the diluent to obtain good peak shapes.

\subsection{Optimization of Chromatographic Conditions for UHPLC}

The satisfactory chromatographic separation, with good peak shapes were achieved on ACQUTY UPLC BEH C18 ( $100 \times 2.1) \mathrm{mm}$ with $1.7 \mu \mathrm{m}$ particles, using $0.1 \%$ Perchloric acid (adjusted to $\mathrm{pH} 2.5$ with Triethylamine) as solution A and Acetonitrile as solution B with a flow rate of $0.6 \mathrm{~mL} \cdot \mathrm{min}^{-1}$. The UHPLC gradient program was optimized as: (time $(\mathrm{min}) / \%$ solution B: 0/10, 1.0/60, $1.5 / 80,2.0 / 60,2.5 / 10,3.0 / 10$. The Column temperature as maintained at $35^{\circ} \mathrm{C}$ and the detection was monitored at a wavelength of $215 \mathrm{~nm}$. The injection volume was $2 \mu \mathrm{L}$. Buffer: Acetonitrile $(80: 20, \mathrm{v} / \mathrm{v})$ was used as diluent.

In the optimized gradient conditions MTP, ASP, SA, RMP and ATV were well separated with a resolution $\left(R_{s}\right)$ of greater than 2 and the typical retention times of MTP, ASP, SA, RMP and ATV 1.12, 1.16, 1.27, 1.42 and 1.78 respectively .Peak purity of stressed samples of all the four drug substances were checked by using Acquity Photo diode array detector. All stressed samples of the drug product (heat $\left(100^{\circ} \mathrm{C}\right)$, acid hydrolysis $(0.1 \mathrm{~N} \mathrm{HCl})$, base hydrolysis $(0.1 \mathrm{~N} \mathrm{NaOH})$, water hydrolysis and oxidation $\left(5 \% \mathrm{H}_{2} \mathrm{O}_{2}\right)$ were analyzed for extended run time of 60 min to check the late eluting degradants.

\subsection{Results of Forced Degradation Study Specificity/Application of Stress (Forced Degradation Study)}

Singh and Bakshi suggested target degradation of $20 \%$ $30 \%$ when establishing the stability-indicating properties of analytical methods, because even intermediate degradation products should not interfere with any stage of drug analysis. Stress studies on combination of all the four drugs under different stress conditions suggested the following degradation behavior. The combination of the drugs showed considerable stability under thermal conditions.

The method was found to be high degree of specificity to the drugs viz ASP, ATV, RMP, and MTP. All drugs were well separated from one another as well as resolved from degraded impurities. The specificity of the method was confirmed by the separation of all the peaks in the degraded samples obtained under different conditions.

The mixture of all the four drug components was exposed to $0.1 \mathrm{~N} \mathrm{HCl}$ at $100^{\circ} \mathrm{C}$ for $1 \mathrm{~h}$. ASP and ATV Showed considerable degradation with time in $0.1 \mathrm{~N} \mathrm{HCl}$ with the formation of Salicylic acid (SA) as the major degradant Figure 2.

When treated under basic conditions, ASP and RMP has shown significant degradation immediately in $0.1 \mathrm{~N}$ $\mathrm{NaOH}$ with ASP is converted into salicylic acid (SA) (Figure 3).

Under oxidation conditions, ASP and ATV has

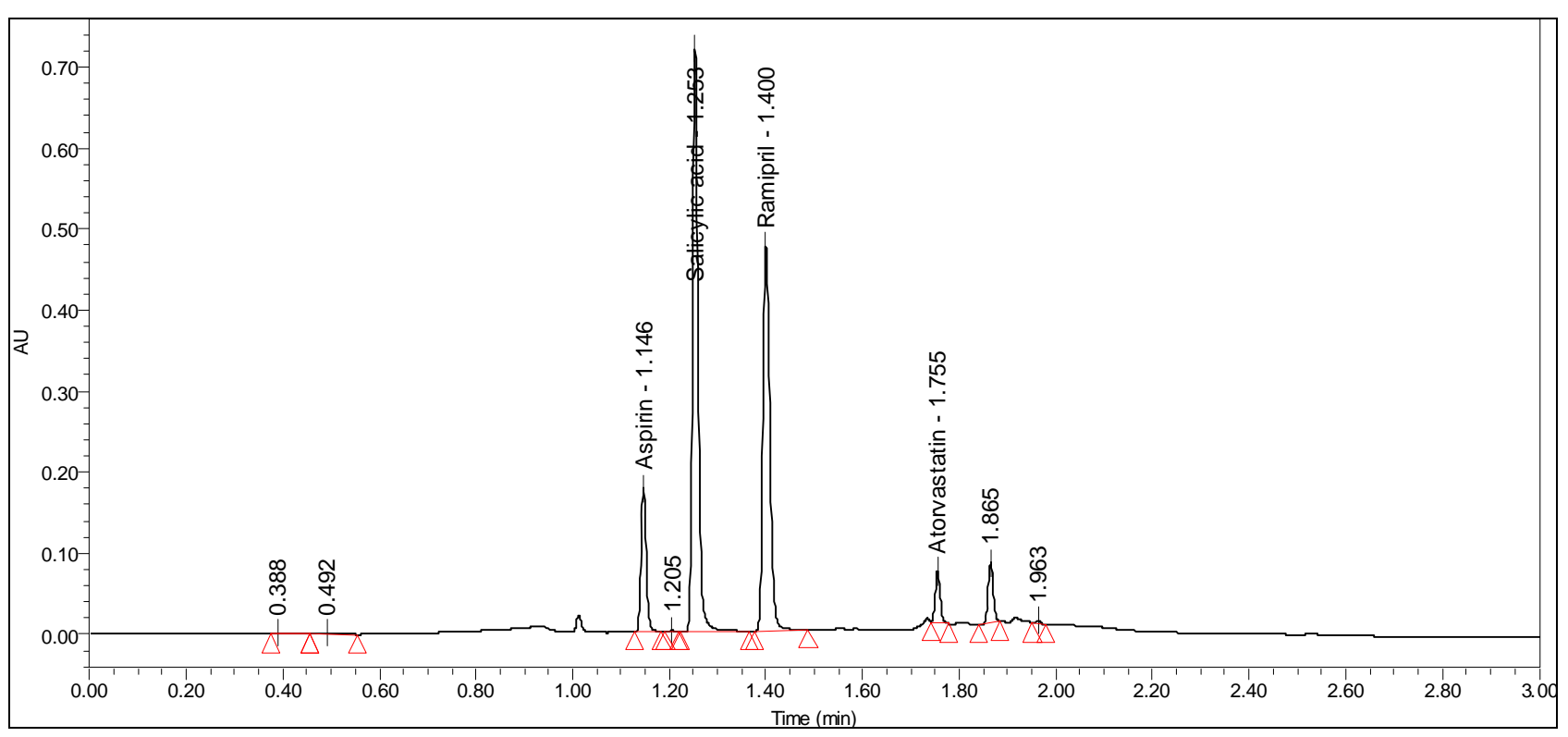

Figure 2. Typical chromatogram of acid degradation, $0.1 \mathrm{~N} \mathrm{HCl}\left(100^{\circ} \mathrm{C}, 1 \mathrm{~h}\right)$. 


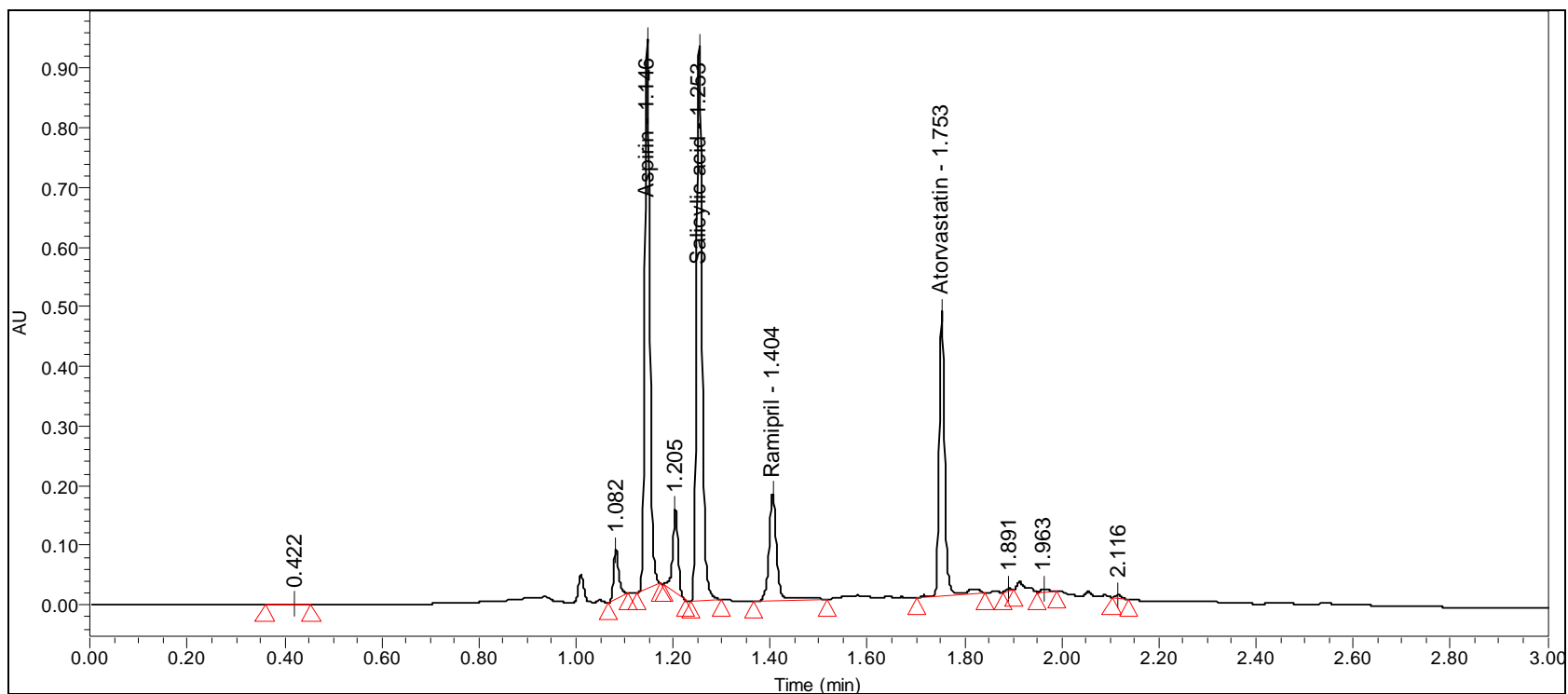

Figure 3. Typical chromatogram of base degradation, $0.1 \mathrm{~N} \mathrm{NaOH}$ (under reflux, $0.5 \mathrm{~h}$ ).

showed considerable degradation by the treatment of 5 hydrogen peroxide. Typical chromatogram is as shown in Figure 4.

All the four drug combinations were exposed to light for an overall illumination of 1.2 million lux hours and an integrated near ultraviolet energy of 200-watt hours/ square meter (w/m hr) (in photo stability chamber. Major degradation observed with ATV (Figure 5).

The proposed method is applied for the assay analysis of 3 different batches of the Zycad. The assay results obtained were within the specification limit. The assay of Polypill is unaffected in the presence of degradation impurities confirming the stability indicating power of the developed method. The stability indicating nature of the method was further confirmed by injecting three month accelerated stability sample and observed that all the degradants were well separated from the main components.

For all the stressed sample injections, peak purity was checked by using a Acquity photo diode array detector (PDA). Peak purity test results derived from PDA detector, confirmed that the all the four drug components were homogeneous and pure in all the analyzed stress samples.

\subsection{Analytical Method Validation:}

The developed chromatographic method was validated for selectivity, linearity, range, precision, accuracy, sensitivity, robustness and system suitability. The typical chromatogram of System suitability shown in Figure 6. The results of system suitability were depicted in Table 1.

\subsubsection{Precision}

The percentage RSD values for the assays in precision study were $0.4 \%, 0.8 \%, 0.4 \%, 0.5 \%$ (inter-day precision) and $0.5 \%, 0.8 \%, 0.6 \%, 0.7 \%$ (intra-day precision) for ASP, ATV, RMP, and MTP confirming a good precision and the ruggedness of the method.

\subsubsection{Sensitivity}

The limits of detection (LOD) and quantitation (LOQ) were established at signal-to-noise ratios of $3: 1$ and 10:1, respectively. The LOD and LOQ of ASP, ATV, RMP and MTP were determined experimentally by injecting each drug six times. The LOD for ASP, ATV, RMP and MTP were $0.1,0.2,0.25$ and $0.12 \mu \mathrm{g} \cdot \mathrm{mL}^{-1}$ respectively. The LOQ for ASP, ATV, RMP and MTP were 0.3, 0.7, 0.8 and $0.4 \mu \mathrm{g} \cdot \mathrm{mL}^{-1}$, respectively.

\subsubsection{Linearity}

The linear ranges were from $\left(\left(37.5\right.\right.$ to $150.0 \mu \mathrm{g} \cdot \mathrm{mL}^{-1}$ for ASP, 5.0 to $20.0 \mu \mathrm{g} \cdot \mathrm{mL}^{-1}$ for ATV and 2.5 to 10.0 $\mu \mathrm{g} \cdot \mathrm{mL}^{-1}$ for RMP and 25.0 to $100.0 \mu \mathrm{g} \cdot \mathrm{mL}^{-1}$ for MTP). The correlation coefficient Obtained was greater than 0.999 .

The Slope and the Intercept value obtained from the linear regression graph is as shown in (Table 2). The result shows an excellent correlation existed between the peak area and concentration of the analyte in the range $50 \%-200 \%$ of analyte concentration

\subsubsection{Accuracy}

The percentage recovery obtained was in the range of $99.02 \%$ to $100.8 \%$. The results indicate the method enables highly accurate simultaneous determination of the 


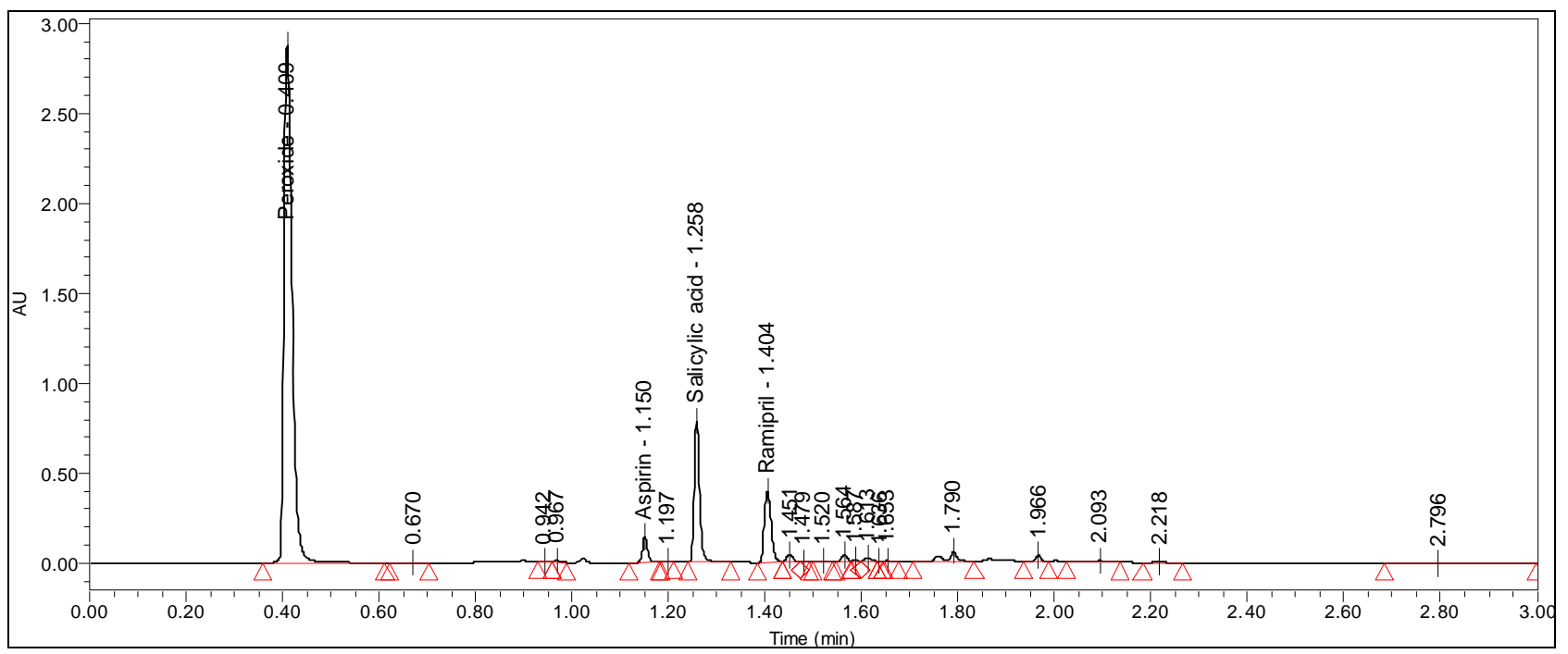

Figure 4. Typical chromatogram of Peroxide degradation, 5\% hydrogen peroxide (RT, 8 h).

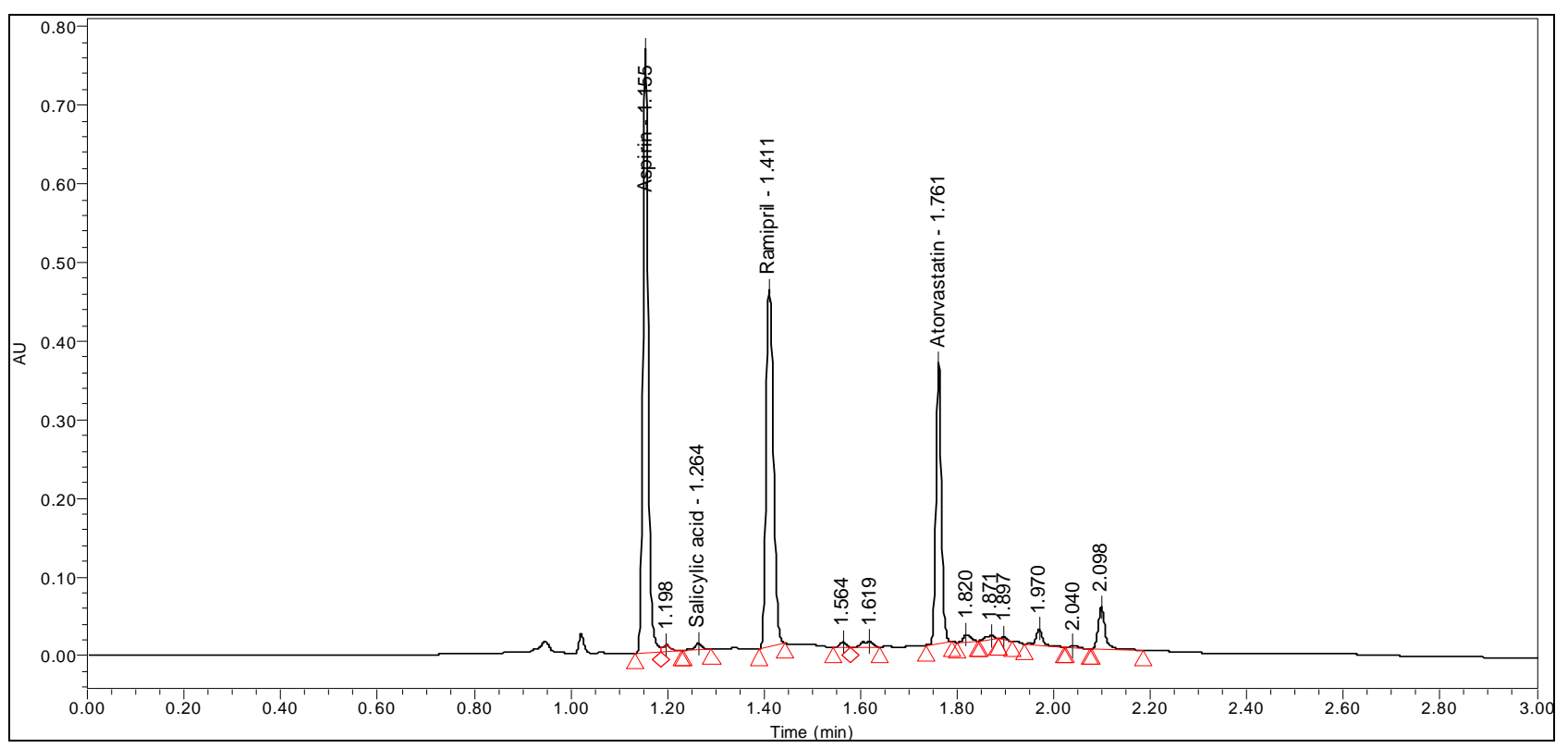

Figure 5. Typical chromatogram of photo stability degradation.

all the four drugs in the Polypill combination.

\subsubsection{Robustness}

The results obtained by deliberate variation in method parameters and data are summarized in Table 3 . The data revealed that the resolution between closely eluting peaks, namely ASP and MTP was always greater than 2.0 and also there was not much effect on the peak shapes, illustrating the robustness of the method

\subsubsection{Solution Stability and Mobile Phase Stability}

The \% RSD of assay of Polypill during solution stability and mobile phase stability experiments was less than 1.0.
No significant changes were observed in the content of ASP, ATV, RMP, and MTP during the study. The solution stability and mobile phase stability experiments data confirms that sample solutions and mobile phase used during assay determination were stable up to the study period of $48 \mathrm{~h}$.

Assay analysis was performed for different batches of the drug product in tablets $(n=3)$, with the targeted analyte concentration. The assay results obtained for the three Zycad Polypill tablets were, ZYD/001 (99.7\% ASP, 99.8\% ATV, 100.2\% RMP and 99.6\% MTP), ZYD/002 (99.6\% ASP, 100.3\% ATV, 99.4\% RMP and 99.8\% MTP) and ZYD/003 (100.1\% ASP, 99.9\% ATV, 99.7\%. 


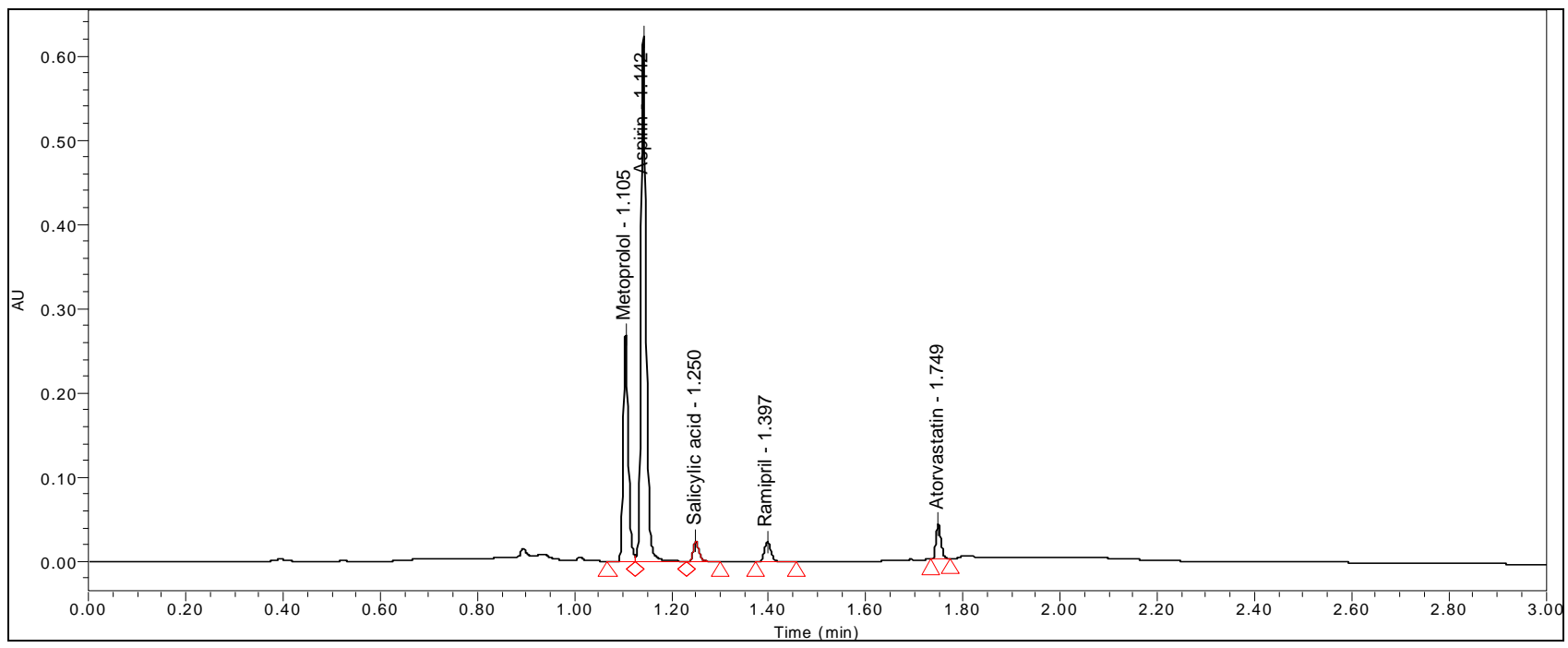

Figure 6. Typical chromatogram of System suitability.

Table 1. System suitability results.

\begin{tabular}{ccccc}
\hline Compound & Retention time & USP Resolution $\left(R_{S}\right)$ & $\begin{array}{c}\text { USP } \\
\text { Tailing factor (T) }\end{array}$ & USP Plate count $(\boldsymbol{N})$ \\
\hline MTP & 1.12 & & 1.14 & 58245 \\
ASP & 1.16 & 2.08 & 1.11 & 60939 \\
SA & 1.27 & 5.42 & 1.14 & 64823 \\
RMP & 1.42 & 6.68 & 1.15 & 60868 \\
ATV & 1.78 & 16.86 & 1.05 & 137740 \\
\hline
\end{tabular}

Table 2. Result of Linearity study.

\begin{tabular}{ccccc}
\hline & ASP & ATV & RMP & MTP \\
\hline Calibration Equn. & $\mathrm{Y}=4690 \mathrm{X}+3976$ & $\mathrm{Y}=907 \mathrm{X}-6273.8$ & $\mathrm{Y}=292 \mathrm{X}-4881.7$ & $\mathrm{Y}=200 \mathrm{X}-710.3$ \\
Linearity Range & $50 \%-200 \%$ & $50 \%-200 \%$ & $50 \%-200 \%$ & $50 \%-200 \%$ \\
$\mathrm{R}^{2}$ & 0.999 & 0.999 & 0.997 & 0.999 \\
Slope & 4689.9 & 907 & 292.4 & 1909.9 \\
Intercept & 3976 & -6273.8 & -4881.7 & -710.3 \\
\hline
\end{tabular}

Table 3. Result of Robustness study.

\begin{tabular}{cccc}
\hline S.No & Parameter & Variation & Resolution $\left(\boldsymbol{R}_{\boldsymbol{s}}\right)$ between MTP and ASP \\
\hline \multirow{2}{*}{1} & $\begin{array}{c}\text { Temperature }\left( \pm 5^{\circ} \mathrm{C}\right. \\
\text { of set temperature })\end{array}$ & (a) At $30^{\circ} \mathrm{C}$ & 2.1 \\
& & (b) At $40^{\circ} \mathrm{C}$ & 1.9 \\
2 & Flow rate $( \pm 20 \%$ of the set flow) & (a) At $0.55 \mathrm{~mL} \cdot \mathrm{min}^{-1}$ & 2.0 \\
& & (b) At $0.65 \mathrm{~mL} \cdot \mathrm{min}^{-1}$ & 1.9 \\
3 & $\mathrm{pH}$ Buffer & (a) $\mathrm{pH} 2.4$ & 1.9 \\
& & (b) $\mathrm{pH} 2.6$ & 2.0 \\
\hline
\end{tabular}

Table 4. Batch analysis for Zycad drug product.

\begin{tabular}{cccc}
\hline Batch No: & $\begin{array}{c}\text { ASP } \\
\text { (\%assay) }\end{array}$ & $\begin{array}{c}\text { ATV } \\
\text { (\%assay) }\end{array}$ & $\begin{array}{c}\text { RMP } \\
\text { (\%assay) }\end{array}$ \\
\hline ZYD/001 & 99.7 & 99.8 & 100.2 \\
ZYD/002 & 99.6 & 100.3 & 99.4 \\
ZYD/003 & 100.1 & 99.9 & 99.6 \\
\hline
\end{tabular}


RMP and 100.3\% MTP) depicted in Table 4.

\subsection{Application of the Method to Stability Study}

Accelerated conditions stability studies are performed to establish the stability indicating nature of the method. Accelerated conditions (temperature $40 \pm 2{ }^{\circ} \mathrm{C}$, relative humidity $75 \pm 5 \%$ ) stored sample of the four drug combinations were analyzed by use of the developed UHPLC method after the period of 3 months. The results obtained clearly indicates that the method is able to separate all the drug-drug interaction impurities or any other degradation impurities formed during the storage conditions, indicating the method was stability-indicating and highly suitable for drug stability studies and for monitoring the quality of the Polypill.

\section{Acknowledgements}

The authors wish to thank the management of United States Pharmacopeia laboratory- India for supporting this work

\section{References}

[1] G. Sanz and V. Fuster, "Fixed-Dose Combination Therapy and Secondary Cardiovascular Prevention: Rationale, Selection of Drugs and Target Population," Nature Clinical Practice Cardiovascular Medicine, Vol. 6, No. 2, 2009), pp. 101-110. doi:10.1038/ncpcardio1419

[2] “Global Burden of Disease 2004 Update," World Health Organization, 2008.

[3] C. D. Mathers and D. Loncar, "Projections of Global Mortality and Burden of Disease from 2002 to 2030," PLoS Medicine, Vol. 3, No. 11, 2006, p. e442. doi:10.1371/journal.pmed.0030442

[4] M. R. Law and N. J. Wald, "Risk Factor Thresholds: Their Existence under Scrutiny," British Medical Journal, Vol. 324, No. 7353, 2002, pp. 570-576. doi: $10.1136 / \mathrm{bmj} .324 .7353 .1570$

[5] V. Kumar, R. P. Shah and S. Singh, "LC and LC-MS Methods for the Investigation of Polypills for the Treatment of Cardiovascular Diseases: Part.1 Separation of Active Compo," Journal of Pharmaceutical and Biomedical Analysis, Vol. 47, 2008, pp. 508-515. doi:10.1016/i.jpba.2008.01.041

[6] S. P. Clissold, "Aspirin and Related Derivatives of Salicylic Acid,” Drugs, Vol. 32, 1986, pp. 8-26. doi:10.2165/00003495-198600324-00003

[7] D. G. Julian, D. A. Chamberlain and S. J. Pocock, "A Comparison of Aspirin and Anticoagulation Following Thrombolysis for Myocardial Infarction (the AFTER Study): A Multicentre Unblinded Randomized Clinical Trial," BMJ (British Medical Journal), Vol. 313, No. 7070, 1996, pp. 1429-1431.

[8] J. W. Nawrocki, S. R. Weiss, M. H. Davidson, D. L.
Sprecher, S. L. Schwartz, P. J. Lupien, P. H. Jones, H. E. Haber, et al., "Reduction of LDL Cholesterol by $25 \%$ to $60 \%$ in Patients with Primary Hypercholesterolemia by Atorvastatin, a New HMG-CoA Reductase Inhibitor," Arteriosclerosis, Thrombosis, and Vascular Biology, Vol. 15, No. 5, May 1995, pp. 678-682. doi:10.1161/01.ATV.15.5.678

[9] L. Pilot, M. Abrahamowicz, M. Eisenberg, K. Humphries, H. Behlouli and J. V. Tu, "Effect of Different Angiotensin-Converting-Enzyme Inhibitors on Mortality among Elderly Patients with Congestive Heart Failure," Canadian Medical Association Journal, Vol. 178, No. 10, 2008, pp. 1303-1311. doi:10.1503/cmaj.060068

[10] Q. Zhang, H. Jin, L. Wang, J. Chen, C. Tang and J. Du, "Randomized Comparison of Metoprolol Versus Conventional Treatment in Preventing Recurrence of Vasovagal Syncope in Children and Adolescents," International Medical Journal of Experimental and Clinical Research, Vol. 14, No. 4, pp. 199-203.

[11] E. R. Montgomery, S. Taylor, J. Segretario, et al., "Development and Validation of a Reversed-Phase Liquid Chromatographic Method for Analysis of Aspirin and Warfarin in a Combination Tablet Formulation," Journal of Pharmaceutical and Biomedical Analysis, Vol. 15, No. 1, 1996, pp. 73-82.

[12] S. Erturk, A. E. Sevinc, L. Ersoy and S. Ficicioglu, "HPLC Method for the Determination of Atorvastatin and Its Impurities in Bulk Drug and Tablets," Journal of Pharmaceutical and Biomedical Analysis, Vol. 33, No. 5, 2003, pp. 1017-1023. doi:10.1016/S0731-7085(03)00408-4

[13] A. Puratchikody, R. Valarmathy and P. Shiju, "RP-HPLC Determination of Atorvastatin Calcium in Solid Dosage Forms," Journal of Pharmacological Reviews, 2003, pp. 79-80.

[14] H. J. Panchal, B. N. Suhagia, N. J. Patel, I. S. Rathod, B. H. Patel, "Development and Validation of a HPTLC Method for the Simultaneous Estimation of Atorvastatin Calcium and Ezetimibe," Chromatographia, Vol. 69, No. 1-2, 2009, pp. 91-95. doi:10.1365/s10337-008-0831-Z

[15] F. Belal, I. A. Al-Zaagi, E. A. Gadkariem and M. A. Abounassif, "A Stability-Indicating LC Method for the Simultaneous Determination of Ramipril and Hydrochlorothiazide in Dosage Forms," Journal of Pharmaceutical and Biomedical Analysis, Vol. 24, No. 3, 2001, pp. 335-342. doi:10.1016/S0731-7085(00)00474-X

[16] M. B. Shankar, F. A. Metha, K. K. Bhatt, R. S. Metha and M. Geetha, "Simultaneous spectrophotometric determination of losartan potassium and hydrochlorothiazide in tablets," Indian Journal of Pharmaceutical Sciences, Vol. 65, No. 2, 2003, pp. 167-170.

[17] "ICH Stability Testing of New Drug Substances and Products Q1A (R2)," International Conference on Harmonization, IFPMA, Geneva, 2003.

[18] "ICH guidelines on Validation of Analytical Procedures, Text and Methodology Q2 (R1)," FDA, Published in the Federal Register 60, 1995.

[19] "United States Pharmacopoeia," 32nd Edition, United 
States Pharmacopeial Convention, Rockville, USP 32, 2009.

[20] M. Bakshi and S. Singh, "Development of Validated Stability-Indicating Assay Methods-Critical Review,"
Journal of Pharmaceutical and Biomedical Analysis, Vol. 28, 2002, pp. 1011-1040. 